\title{
Acceptability of notifications delivered to older adults by technology-based assisted living services
}

Authors: Loïc Caroux ${ }^{1}$, Charles Consel ${ }^{2,3}$, Margaux Merciol ${ }^{2}$, Hélène Sauzéon ${ }^{2,4}$

Affiliations:

1. CLLE, University of Toulouse, CNRS, UT2J, France

2. Inria, Talence, France

3. Bordeaux Institute of Technology, Talence, France

4. Laboratoire Handicap, Activité, Cognition et Santé, University of Bordeaux, Bordeaux, France

Email addresses:

loic.caroux@univ-tlse2.fr ; charles.consel@inria.fr ; mmerciol@hotmail.fr ; helene.sauzeon@inria.fr

Corresponding author:

LoÏc CAROUX

Laboratoire CLLE - Maison de la Recherche

Université Toulouse Jean Jaurès

5 Allées Antonio Machado

31058 Toulouse Cedex 9

France

E-mail: loic.caroux@univ-tlse2.fr

Acknowledgements : This work was supported by the Conseil Régional d'Aquitaine, the Conseil

Départemental de la Gironde, the Caisse Nationale de la Solidarité pour l'Autonomie (CNSA), the

Caisse d'Assurance Retraite et de la Santé au Travail (CARSAT), the Union Départementale des

Centres Communaux d'Action Sociale de Gironde (UDCCAS 33), and the Chambre des Métiers. 


\section{Abstract}

Purpose: The goal of this research is to study the acceptability of notifications delivered to older adults by technology-based assisted living services. Because computing systems are now ubiquitous, interruption management has become an important issue. It has been previously shown that the acceptability of interrupting notifications delivered by technology-based assistive services is influenced by their level of urgency and intrusiveness. However, these studies have mostly been focusing on younger adults and fall short of showing the role played by the nature of the interrupted user's activity.

Methods: This article presents an experimental study that involved older old adults $(M=82)$ placed in different fictional situations of interruption by a notification during an activity of daily living (ADL).

Results: The level of both urgency and intrusiveness influences the acceptability of notifications. More interestingly, both the nature of the ADLs (basic/instrumental) and the main resources engaged in the activity (cognitive/physical) influence the acceptability of notifications. Notifications are less accepted if the interrupted $A D L$ is an instrumental one that mainly engages cognitive resources.

Conclusions: These findings provide important clues to demonstrate that assistive services should be context-aware, at least for this population. Before delivering a notification, the assistive system should be aware of the type of activity the user is performing and decide whether the time to notify the user is appropriate, or whether the notification should be postponed.

\section{Keywords}

Interruption management, activities of daily living, context awareness, urgency, intrusiveness. 


\section{Introduction}

Because computing systems are now ubiquitous, interruption management has become an important issue for modern workplaces, which involve more and more multi-task activities [18], as well as for daily life activities [32]. Users must manage interruptions by notifications of any kind from typical computing systems such as smartphones or tablets, but also from other connected objects in the home, such as thermostats or household appliances [11].

These systems are no longer used only by younger people at their best. They are more and more used in a context of assistance towards people with special needs [10]. In particular, aging in place often involves systems which have to be used by older people, including the old oldest ones $[6,13$, 15, 38]. There is a range of such platforms and devices for assisted living that have been developed for older adults, see $[8,24,25]$ for examples of surveys. Areas of assistive services include family/peer interaction [2] (e.g., PeerCare [26], Message Center [37], email applications [7]), monitoring daily activities (e.g., Digital family portraits [27], DigiSwitch [4]), and monitoring healthrelated activities (e.g., medication taking $[23,28])$.

It has been widely shown in the literature that being interrupted while performing a task may be disruptive for an individual. Not only can it have a negative impact on the performance of the task, but it can also degrade the well-being of the individual. In the literature, the concept of interruption management refers to a user or an operator performing a primary task, being interrupted by an alert for a secondary task, and eventually returning to the interrupted task, see [30] for a review. Interruption management has mainly been studied in domains where problems of primary task resumption can have serious consequences. For example, previous studies investigated interruption management by air and maritime traffic regulation operators [19, 29], car drivers [21], and healthcare clinicians or nurses $[5,36]$.

Interruption management mainly involves task switching abilities, as well as prospective and working memory capacities of the user $[14,30]$. In case of disruptive interruption, the performance of the 
primary task may be impaired in terms of amount of time of completion, amount of time of resumption, number of errors made, and even abandonment of the task. Furthermore, the disruption may impair the affective state of the individual, by increasing feelings of stress and frustration.

Interrupting daily life activities may be less impacting when situations are not critical and when individuals are younger adults who have sufficient cognitive capabilities to cope with task switching. In contrast, consequences could be more serious for users with low or declining cognitive abilities, such as older adults. Task switching abilities and working memory capacities can be very limited in older adults, see [3] for a review. Indeed, a major consequence of cognitive decline in older adults is the progressive loss of the ability to perform activities of daily life (ADLs) [17]. At a minimum, a poor management of task interruption may decrease the acceptance of the technologies responsible for these interruptions, causing their rejection or abandonment. But more importantly, the users' safety and health could be at risk.

Recent studies in human-computer interaction investigated how technology should be designed to improve the acceptability of interruptions by notifications in ADLs. They argue that the most effective lever for improving notification systems is to make them context-aware. Notifications should be delivered at the most appropriate time, with a level of intrusiveness related to its level of urgency [1]. Empirical studies of context-aware notification systems support the fact that their acceptability is influenced by the level of urgency and intrusiveness of notifications, e.g., [31, 32], even when targeting users with sensory impairments and using multimodal interactions [34, 35]. However, these studies fall short of showing the role played by the nature of the user activity being interrupted by a notification. We conjecture that this situation is due to the fact that they have mostly been focusing on younger adults. Specific empirical studies are needed to measure the acceptability of notifications delivered to older adults while they perform ADLs. 
In this paper, we present an experimental study on the acceptability of notifications delivered to older adults by technology-based assisted living services. Our goal is to show that, because older adults tend to have limited task switching and working memory capacities, their acceptance of notifications is influenced by the levels of urgency and intrusiveness of the notifications and the nature of the activity being interrupted by a notification. In this experiment, older adults are placed in different fictional situations of interruption by a notification during an ADL. Each situation varies in terms of key parameters of acceptability of notifications, namely, the level of urgency (critical/noncritical content), the level of intrusiveness of the notifications (loud/soft tone), the nature of the ADLs (basic/instrumental), and the main resources engaged in these activities (cognitive/physical). Participants' acceptability of notifications was assessed for each situation with a multi-dimensional questionnaire.

Basic ADLs correspond to physical self-care tasks, such as dressing and toileting [20]. Instrumental ADLs entail more cognitively complex tasks, including meal preparation or medication management [22]. Non-critical notifications are the ones that do not need to be immediately attended by the user; they announce a situation or an information. In contrast, critical notifications correspond to situations of assistance that may involve safety or security; the user's attention is thus requested. Vastenburg et al. [32] have shown in their user study that notification acceptance depends also on whether the level of intrusiveness of a notification is related to its level of urgency. This finding leads us to introduce two tones to announce notifications in the fictional situations: a soft tone (sound of carillon) for non-critical notifications and a loud tone (sound of ambulance siren) for critical notifications.

The present study takes place in the framework of technology acceptance. According to the main models, such as the "Technology Acceptance Model" [12] or the "Unified Theory of Acceptance and Use of Technology" [33], the perceived usefulness and perceived ease of use are predictors of the attitude towards using, which is then a predictor of intention to use and, ultimately, actual use. 
These models highlight the role played by the subject's preexisting perceptions and beliefs on the technology acceptance as well as actual or future technology-use behaviors. As a result, an usercentered technology involves an upstream design phase where user's perceptions are taken account regarding future technology-use scenarios. Specific models of technology acceptance for older people, such as the "Senior Technology Acceptance Model" [9], rely also on the same general principle. Studying the level of acceptability of notifications can be done at each of these steps of the models. By using fictional situations of interruptions by a notification, the present study aims to investigate acceptability in terms of attitude towards using such a technology.

We formulated two hypotheses. Hypothesis 1 was that the level of both urgency and intrusiveness influences the acceptability of notifications. This hypothesis is in conformance with previous studies. We expected that notifications are less acceptable if their content is perceived as non-critical. This hypothesis should even be more easily verified if the notification tones are perceived as intrusive. Hypothesis 2 was that the nature of the ADLs and the main resources engaged in the activity influence the acceptability of notifications. We expected that notifications are less acceptable if they interrupt an activity highly demanding cognitively.

\section{Method}

\subsection{Participants}

A total of 17 older old adults ( 15 females and 2 males) aged 82.4 on average $(S D=7.0$ ) has been recruited from public home services. Older old adults were selected in the present study because they are the main targeted end users of the technology-based assisted living services for aging in place. Also, the mean age of loss of autonomy and need of assistance for older adults living in Europe and North America is about 80 years old. The participants underwent a clinical interview for exclusion criteria; they were excluded if one of the following conditions was reported: History and/or 
presence of alcohol, substance abuse, and neurological and psychiatric disorders. The older participants were screened using the Mini-Mental Status Examination (MMSE) [16] and had a score greater than $27 / 30$ (the mean score of the group was 28.24). This research complied with the tenets of the Declaration of Helsinki (WMA, 2008), and was approved by the ethics committee of the University of Bordeaux. Informed consent was obtained from each participant.

\subsection{Material}

Four kinds of material were designed in the present study: messages of the notifications, tones of the notifications, scenarios of the fictional situations of interruption by notifications, and a multidimensional questionnaire.

Table 1 displayed the four different messages that were designed on the basis on typical notifications in a connected home. They were printed in black on white sheets of paper with classic fonts (Arial, 48pt). They were pre-categorized within two levels of urgency (critical/non-critical).

Table 1. Notification messages used in the experiment.

\begin{tabular}{ll}
\hline Type of message & Message \\
\hline Critical & Warning: the stove has been left on a long time. Fire hazard! \\
Critical & Warning: the front door was left open. Risk of intrusion! \\
Non-critical & Reminder: You have an appointment with your caregiver tomorrow at 4:00 pm. \\
Non-critical & Reminder: Your electricity bill must be paid before the end of the week. \\
\hline
\end{tabular}

To announce a notification to the participant, a tone was played for 2 seconds using a laptop speaker: carillon for non-critical notifications and ambulance siren for critical ones. Four fictional scenarios of daily activities were designed, according to the nature of the interrupted activity (basic/ instrumental). Two scenarios concerned basic ADLs (dressing and watching TV). The other two scenarios concerned instrumental ADLs (doing the laundry, doing the books). The scenarios were designed according to the level of physical or cognitive resources engaged by the older adult in the activity. Two scenarios mainly engaged physical resources (dressing, doing the laundry). The other 
two scenarios mainly engage cognitive resources (watching TV, doing the books). The scenarios were given orally to the participants by the experimenter. The texts of the scenarios are detailed in Table 2.

Table 2. Scenarios of interrupted activities used in the experiment.

\begin{tabular}{|c|c|c|}
\hline $\begin{array}{l}\text { Nature of } \\
\text { the activity }\end{array}$ & $\begin{array}{l}\text { Main resources } \\
\text { engaged }\end{array}$ & Text of the scenario \\
\hline Basic & Cognitive & $\begin{array}{l}\text { You are now sitting in your living room and watching a relaxing } \\
\text { program on TV. A tone is played to announce a notification. }\end{array}$ \\
\hline Basic & Physical & $\begin{array}{l}\text { You are now in your bedroom, getting dressed. A tone is played } \\
\text { to announce a notification. }\end{array}$ \\
\hline Instrumental & Cognitive & $\begin{array}{l}\text { You are now in your kitchen, sitting at the table doing the } \\
\text { books. A tone is played to announce a notification. }\end{array}$ \\
\hline Instrumental & Physical & $\begin{array}{l}\text { You are now in your laundry room, putting clothes in the } \\
\text { washing machine. A tone is played to announce a notification. }\end{array}$ \\
\hline
\end{tabular}

A questionnaire composed of 6 statements was used to assess the acceptability of notifications for each situation (Table 3). The design of this questionnaire was partially based on that used by Vastenburg et al. [32]. The topics of these statements address the general acceptability of notifications ( 1 item), the perceived intrusiveness of the notification tones ( 2 items), the perceived urgency of the notification messages ( 1 item), and the perceived activity interruption ( 2 items). For each statement, a 5-point Likert scale was proposed to collect the responses of the participants (from $1=$ Strongly Disagree to 5 = Strongly Agree) .

Table 3. Items of the questionnaire of acceptability used in the experiment.

\begin{tabular}{ll}
\hline Item number & Statement \\
\hline 1 & Receiving this notification disrupted me. \\
2 & Hearing the notification tone was intrusive. \\
3 & The notification tone should have been less intrusive. \\
4 & The notification message was urgent. \\
5 & The interrupted activity was urgent. \\
\hline
\end{tabular}




\subsection{Design and procedure}

The experimental design was a $2 \times 2 \times 2 \times 2$ design with the levels of urgency (critical/non-critical content) and intrusiveness (loud/soft tone) of the notifications, as well as the nature of the interrupted activities (BADL/IADL) and the main resources engaged in them (cognitive/physical) as factors. These factors were manipulated within participants. The combination of these factors resulted in 16 experimental conditions. Each condition was repeated twice with two different messages per condition. The total number of experimental trials (different situations) was 32 . The order of presentation of these trials was randomized for each participant. Each trial was composed of the same steps. First, the experimenter read the fictional scenario of home activity to the participant. The participants were asked to imagine they were actually performing the situation in their own home. Second, once the text was read, the notification tone was displayed. Third, the content of the notification message was (visually) displayed and the participant was asked to read the message. Fourth, the participant answered to the 6-item questionnaire (Table 3).

\subsection{Dependent measures}

The six measures used in the present experiment were the six subjective ratings given by the participants in the questionnaire of acceptability for each trial. These variables were analyzed using two sets of factorial repeated measures ANOVAs. Each set was linked to each hypothesis. The first set of ANOVAs was performed with the levels of urgency and intrusiveness of the notifications as within-participants factors. The second set of ANOVAS was performed with the nature of the interrupted activities and the main resources engaged in their performance as within-participants factors. 


\section{Results}

\subsection{General acceptability of notifications (Item 1)}

Figure 1 shows that the level of urgency impacted the general acceptability of notifications $(F=$ $\left.67.53, p<.001, \eta_{p}^{2}=.81\right)$. Receiving critical messages is more acceptable than receiving non-critical messages. The level of intrusiveness also impacted the general acceptability of notifications $(F=5.22$, $\left.p<.05, \eta_{p}^{2}=.25\right)$, and the interaction between these two factors was significant $\left(F=7.27, p<.05, \eta_{p}^{2}\right.$ $=.31)$. The level of intrusiveness had an impact only when messages were non-critical. In this case, receiving non-critical messages is less acceptable when notifications are intrusive (with loud tone) than when they are not intrusive (with soft tone).

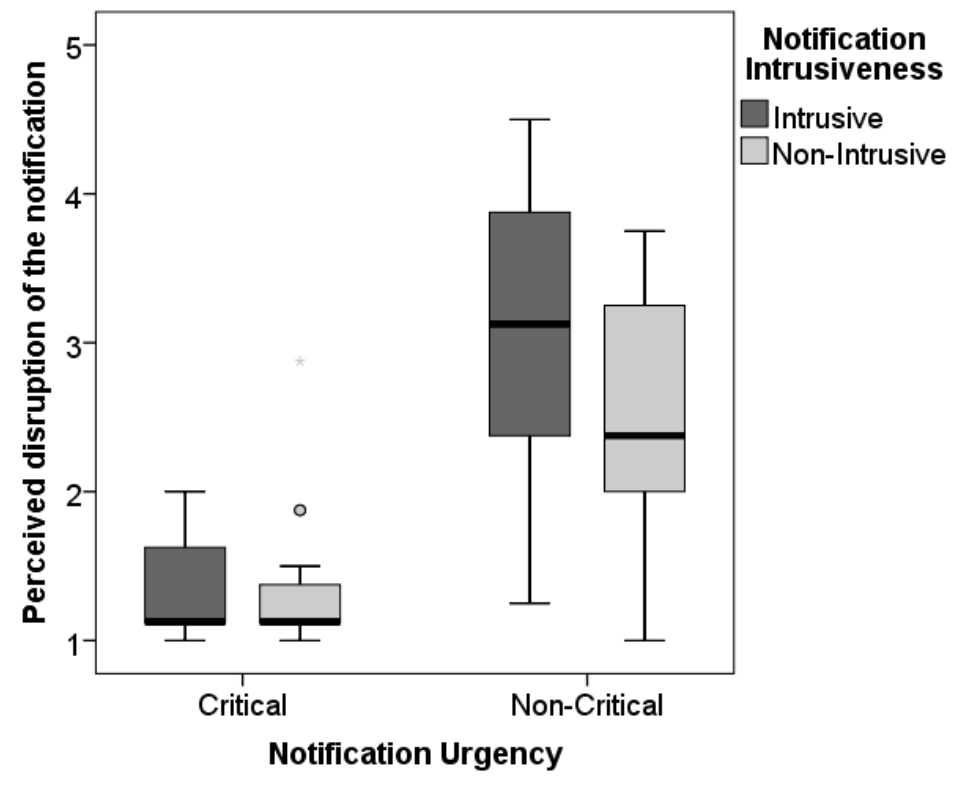

Figure 1. Box-plots of the perceived disruption of the notification according to the levels of both notification urgency and intrusiveness. The vertical axe ranges from 1 (low) to 5 (high). Circles denote outliers, stars denote extreme values.

Figure 2 shows that the interaction between the nature of the interrupted activities and the main resources engaged in them was significant $\left(F=5.15, p<.05, \eta_{p}^{2}=.24\right)$. Being interrupted during 
IADLs that mainly engage cognitive resources is less acceptable than during IADLs that mainly engage physical resources. There was no significant difference between both BADLs activities, or between IADLs and BADLs activities.

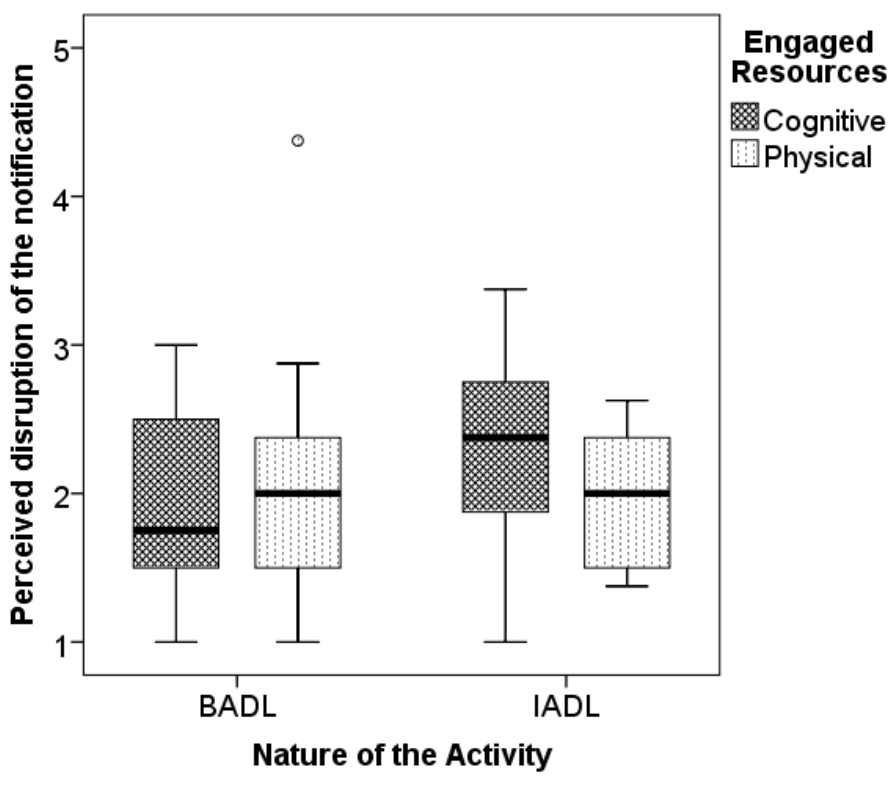

Figure 2. Box-plots of the perceived disruption of the notification according to the nature of the interrupted activity and the main resources engaged in its performance. The vertical axe ranges from 1 (low) to 5 (high). Circles denote outliers, stars denote extreme values.

\subsection{Perceived intrusiveness of the notification tones (Items $2-3$ )}

Regarding Item 2 of the questionnaire, Figure 3 shows that the level of notification intrusiveness $(F=$ $\left.36.32, p<.001, \eta_{p}^{2}=.69\right)$ and the level of message urgency $\left(F=15.06, p<.05, \eta_{p}^{2}=.49\right)$ impacted the perceived intrusiveness of the notification tones. The interaction between these two factors was also significant $\left(F=11.59, p<.01, \eta_{p}^{2}=.42\right)$. Perceived intrusiveness was higher when notifications were intrusive (loud tone) than when they were not (soft tone). This difference was even higher when messages were non-critical. 


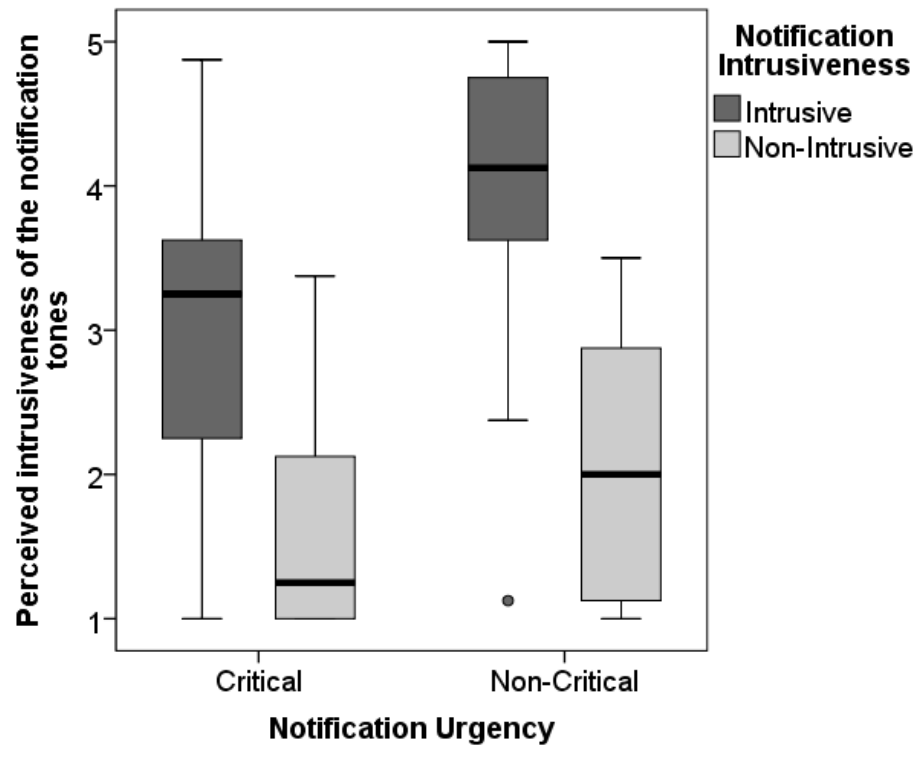

Figure 3. Box-plots of the perceived intrusiveness of the notification tones according to the levels of both notification urgency and intrusiveness. The vertical axe ranges from 1 (low) to 5 (high). Circles denote outliers, stars denote extreme values.

Results were similar for Item 3 of the questionnaire. The level of notification intrusiveness $(F=24.21$, $\left.p<.001, \eta_{p}^{2}=.60\right)$ and the level of message urgency $\left(F=44.07, p<.001, \eta_{p}^{2}=.73\right)$ impacted the preferred level of intrusiveness of the notification tones. The interaction between these two factors was also significant $\left(F=13.52, p<.01, \eta_{p}^{2}=.46\right)$. In the conditions where messages were critical, a less intrusive tone was more preferred when notifications were intrusive $(M=2.09, S D=.99)$ than when they were not $(M=1.45, S D=.66)$. This difference was even higher when messages were noncritical $(M=3.85, S D=1.11$ for intrusive notifications; $M=2.21, S D=1.14$ for non-intrusive notifications).

For both items, there was no significant simple effect or interaction of the factors related to the interrupted activity (nature of the activity and the main resources engaged).

\subsection{Perceived urgency of the notification messages (Item 4)}

The level of message urgency impacted the perceived urgency of the notification messages $(F=$ 87.29, $\left.p<.001, \eta_{p}^{2}=.84\right)$. Perceived urgency was higher when messages were critical $(M=4.84, S D=$ 
$.24)$ than they were none-critical $(M=2.45, S D=1.05)$. There was no significant effect of the level of intrusiveness, nor interaction between both factors.

There was no significant simple effect or interaction of the factors related to the interrupted activity (nature of the activity and the main resources engaged).

\subsection{Perceived activity interruption (Items $5-6$ )}

Regarding the perceived urgency of the interrupted activity (Item 5), Figure 4 shows that the nature of the interrupted activities had an impact $\left(F=8.71, p<.001, \eta_{p}^{2}=.35\right)$. IADLs were perceived as more urgent than BADLs. There was also an interaction between the nature of the interrupted activities and the main resources engaged in them was significant $\left(F=20.03, p<.001, \eta_{p}^{2}=.56\right)$. The mainly cognitive activity was perceived as more urgent than the mainly physical one in the case of IADLs. In contrast, the mainly physical activity was perceived as more urgent than the mainly cognitive one in the case of BADLs.

There were no significant simple effects or interaction of both levels of notification intrusiveness and message urgency. 


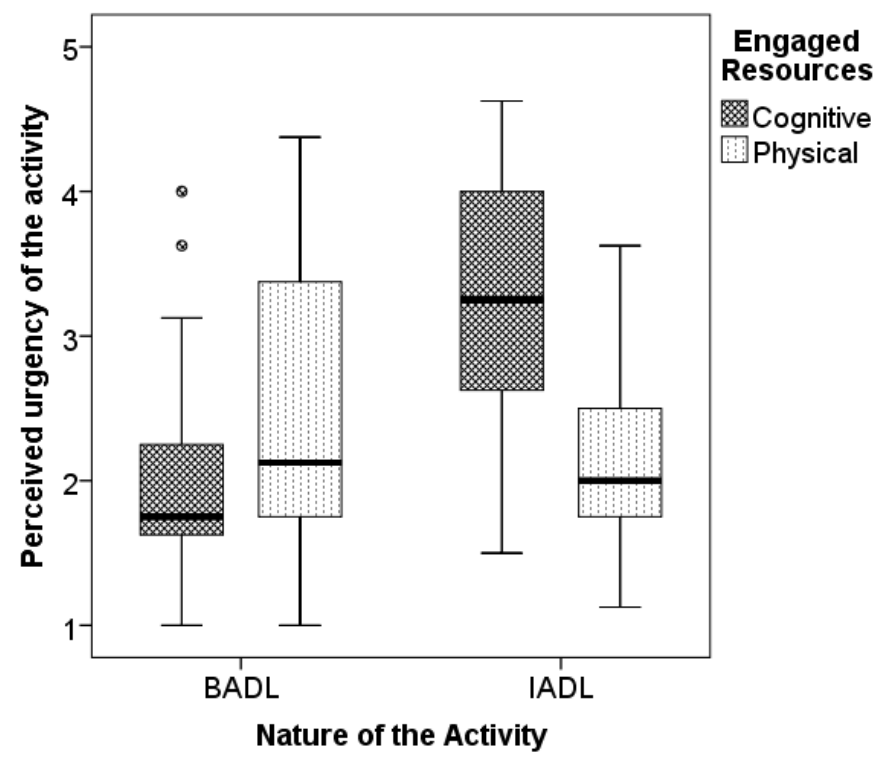

Figure 4. Box-plots of the perceived urgency of the activity according to the nature of the interrupted activity and the main resources engaged in its performance. The vertical axe ranges from 1 (low) to 5 (high). Circles denote outliers, stars denote extreme values.

Regarding the perceived appropriateness of the time of interruption (Item 6), the level of message urgency had an impact $\left(F=57.19, p<.001, \eta_{p}^{2}=.78\right)$. Appropriateness was higher when messages were critical $(M=4.21, S D=.89)$ than when they were non-critical $(M=2.49, S D=.70)$. There was no significant effect of the level of notification intrusiveness, nor interaction between both factors.

As shown in Figure 5, there was an interaction between the nature of the interrupted activities and the main resources engaged in them $\left(F=4.58, p<.05, \eta_{p}^{2}=.22\right)$. In the case of IADLs, appropriateness was lower when the activity mainly engages cognitive resources than when physical resources are mainly engaged. There was no difference between BADLs. 


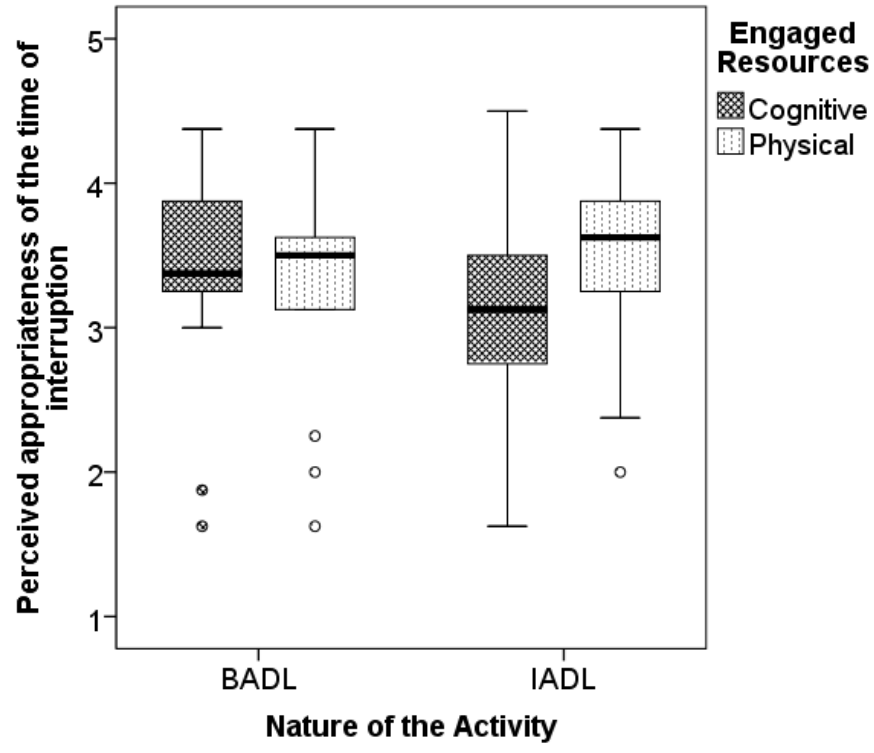

Figure 5. Box-plots of the perceived appropriateness of the time of interruption according to the nature of the interrupted activity and the main resources engaged in its performance. The vertical axe ranges from 1 (low) to 5 (high). Circles denote outliers, stars denote extreme values.

\section{Discussion}

Hypothesis 1 stated that the level of both urgency and intrusiveness influences the acceptability of notifications. This hypothesis was verified by our experiment. As expected, notifications are less acceptable if their content is perceived as non-critical; this is even more pronounced if the notification tones are perceived as intrusive. Results about general acceptability of notifications (Item 1 of the questionnaire) show that participants judged less acceptable to be interrupted by notifications with non-critical content than notifications with critical content. Furthermore, when the content of the notifications is non-critical, the interruption was judged even less acceptable when the tone was loud than when the tone was soft. Results about the perceived intrusiveness of notification tones (Items 2-3) and the perceived urgency of notification messages (Item 4) also support hypothesis 1 . First of all, the perceived levels of both intrusiveness of the tones and urgency of content by the participants were in line with our pre-categorizations. Notifications with loud tone were judged more intrusive than notifications with soft tone. Notifications with critical content were 
judged more urgent than notifications with non-critical content. Then, results showed that the difference of perceived intrusiveness of the notification tones was greater when the messages were non-critical than when they were critical. In fact, the participants would have preferred a less intrusive tone when the tone was intrusive (loud tone). This preference was even more pronounced when messages were non-critical.

These results are in conformance with previous studies that investigated acceptability of notifications for home with younger adults, e.g., [32]. The levels of both urgency and intrusiveness of notifications, as well as the relation between them, influence their acceptability in a similar way for younger and older adults.

Hypothesis 2 stated that the nature of the ADLs and the main resources engaged in the activity influence the acceptability of notifications. Our experiment also supported this hypothesis. Although there was no simple effect of the nature of the interrupted activity (BADL or IADL) or the main resources engaged in them, we observed an interaction of these two factors on notification acceptability. Results about general acceptability (Item 1) showed that participants judged less acceptable to be interrupted by a notification when they are engaged in an IADL that mainly involves cognitive resources than when they are engaged in other types of activities. In other words, notifications are less acceptable if they interrupt an activity highly demanding cognitively. This pattern of results meets the results observed for the perceived level of urgency of the interrupted activity (item 5) and the appropriateness of the time of interruption (item 6). Putting them together, these results showed that notifications are judged less acceptable when they interrupt urgent activities (cognitive IADLs in the present study) than when they interrupt less urgent activities.

These results are in conformance with previous literature about interruption management in the one hand and older adults limited cognitive abilities in the other hand. The disruption triggered by an interrupting task on the ongoing task performance can be higher if the ongoing task is cognitively highly demanding. Then, returning to the ongoing task may be more difficult for the user. In the 
present study, returning to doing the books is perceived as more difficult than returning to watching TV. For younger adults, the difference of difficulty may have no significant impact on acceptability of the interrupting notification. However, as explained earlier, older adults have limited task switching abilities and working memory capacity [3]. Returning to the ongoing task in an effective way requires an amount of cognitive resources that may not be compatible with older adults' capabilities. The consequence is that the acceptability of interrupted notifications is impacted, especially when the ongoing task is cognitively highly demanding.

\subsection{Limitations}

There were some limitations in this experiment that could attenuate these findings. First, we designed fictional situations only. By using fictional situations of interruptions by a notification, the present study aimed to investigate acceptability in terms of attitude towards using such a technology. According to user-centered design approach focusing on user's technology-related expectations and perceptions, this choice is appropriate for a very first study on the topic, and it provides reliable and consistent results with our assumptions. Such findings could be replicated in an ecological setting, with participants placed in real situations of activity interruption, i.e. in situations of actual use of the technology. This kind of study could take place in a lab or in the participants' home. The validity and the power of subjective acceptability would be improved. Furthermore, measures of task performance (e.g., completion time, resumption time, number of errors made) could provide objective data about the influence of the nature of ongoing activities on their interruption by notifications.

Second, the number of scenarios was limited to four; there was only one scenario for each experimental condition of activity (nature $\times$ resources). Further studies should vary the manipulated activities in order to confirm that the observed effects are really due to the manipulation of the nature of the activities or the resources engaged in them, and not due to the activity itself. 


\subsection{Practical implications}

The findings provide important clues about the implication for technology-based assistive services that support ADLs of older adults. They seem to demonstrate that, at least for this population, assistive services should be context-aware. Before delivering a notification, the assistive system should be aware of the type of activity the user is performing and decide whether the time to notify the user is appropriate, or whether the notification should be postponed. For example, we found in the present study that, if the older adult is performing a cognitively highly demanding task, the notification should be postponed. Furthermore, the intrusiveness must be related to the level of urgency of the notification content. We believe that designers of assistive living technology for older adults should use these findings as design principles.

\section{Conclusion}

The goal of the present research was to study the acceptability of notifications delivered to older old adults by technology-based assisted living services. An experiment was designed in which older old adults were placed in different fictional situations of interruptions by a notification during an ADL. In line with previous literature, notifications were judged less acceptable if their content was perceived as non-critical; this was even more pronounced if the notification tones were perceived as intrusive. More interestingly, the participants judged less acceptable to be interrupted by a notification when they supposed to be engaged in an IADL that mainly involves cognitive resources than when engaged in other types of activities. This research provided important clues to demonstrate that assistive services should be context-aware, at least for this population. Nevertheless, by using fictional situations, the present study aimed to investigate acceptability only in terms of attitude towards using such a technology. These findings should be replicated in an ecological setting, with participants placed in real situations of activity interruption, i.e. in situations of actual use of the technology. 


\section{References}

1. Bailey BP, Konstan JA (2006) On the need for attention-aware systems: Measuring effects of interruption on task performance, error rate, and affective state. Comput Hum Behav 22:685-708. doi: 10.1016/j.chb.2005.12.009

2. Borg J, Lantz A, Gulliksen J (2015) Accessibility to electronic communication for people with cognitive disabilities: a systematic search and review of empirical evidence. Univers Access Inf Soc 14:547-562. doi: 10.1007/s10209-014-0351-6

3. Braver TS, West R (2008) Working memory, executive control, and aging. In: Craik FIM, Salthouse TA (eds) The handbook of aging and cognition (3rd ed.), Psychology Press. New York, NY, US, pp 311-372

4. Caine KE, Zimmerman CY, Schall-Zimmerman Z, Hazlewood WR, Sulgrove AC, Camp LJ, Connelly KH, Huber LL, Shankar K (2010) DigiSwitch: Design and evaluation of a device for older adults to preserve privacy while monitoring health at home. In: Proceedings of the 1st ACM International Health Informatics Symposium. ACM Press, pp 153-162

5. Campoe KR, Giuliano KK (2017) Impact of frequent interruption on nurses' patientcontrolled analgesia programming performance. Hum Factors J Hum Factors Ergon Soc 59:1204-1213. doi: 10.1177/0018720817732605

6. Caroux L, Consel C, Dupuy L, Sauzéon H (2018) Towards context-aware assistive applications for aging in place via real-life-proof activity detection. J Ambient Intell Smart Environ 10:445-459. doi: 10.3233/AIS-180505

7. Caroux L, Consel C, Sauzéon H, Dupuy L (2017) Designing an accessible and engaging email application for aging in place. In: Proceedings of the 14th IEEE International Conference on Ubiquitous Intelligence and Computing UIC 2017. San Francisco, USA, p 8p

8. Chan M, Estève D, Escriba C, Campo E (2008) A review of smart homes-Present state and future challenges. Comput Methods Programs Biomed 91:55-81. doi: 10.1016/j.cmpb.2008.02.001

9. Chen K, Chan AHS (2014) Gerontechnology acceptance by elderly Hong Kong Chinese: a senior technology acceptance model (STAM). Ergonomics 57:635-652. doi: $10.1080 / 00140139.2014 .895855$

10. Consel C (2018) Assistive Computing: A human-centered approach to developing computing support for cognition. In: Proceedings of the 40th International Conference on Software Engineering ICSE 2018. p 10p

11. Consel C, Dupuy L, Sauzéon H (2015) A unifying notification system to scale up assistive services. In: Proceedings of the 17th International ACM SIGACCESS Conference on Computers \& Accessibility. ACM, New York, NY, USA, pp 77-87 
12. Davis FD, Bagozzi RP, Warshaw PR (1989) User acceptance of computer technology: A comparison of two theoretical models. Manag Sci 35:982-1003. doi:

$10.1287 / \mathrm{mnsc} .35 .8 .982$

13. Doyle J, Bailey C, Ni Scanaill C, van den Berg F (2013) Lessons learned in deploying independent living technologies to older adults' homes. Univers Access Inf Soc 13:191204. doi: 10.1007/s10209-013-0308-1

14. Drews FA, Musters A (2015) Individual differences in interrupted task performance: One size does not fit all. Int J Hum-Comput Stud 79:97-105. doi:

10.1016/j.ijhcs.2015.01.003

15. Dupuy L, Froger C, Consel C, Sauzéon H (2017) Everyday functioning benefits from an assisted living platform amongst frail older adults and their caregivers. Front Aging Neurosci 9:article 302. doi: 10.3389/fnagi.2017.00302

16. Folstein MF, Folstein SE, McHugh PR (1975) Mini-mental state: a practical method for grading the cognitive state of patients for the clinician. J Psychiatr Res 12:189-198. doi: 10.1016/0022-3956(75)90026-6

17. Gold DA (2012) An examination of instrumental activities of daily living assessment in older adults and mild cognitive impairment. J Clin Exp Neuropsychol 34:11-34. doi: $10.1080 / 13803395.2011 .614598$

18. González VM, Mark G (2004) “Constant, constant, multi-tasking craziness": managing multiple working spheres. In: Proceedings of the SIGCHI Conference on Human Factors in Computing Systems CHI'04. ACM Press, pp 113-120

19. Hodgetts HM, Tremblay S, Vallières BR, Vachon F (2015) Decision support and vulnerability to interruption in a dynamic multitasking environment. Int J Hum-Comput Stud 79:106-117. doi: 10.1016/j.ijhcs.2015.01.009

20. Katz S (1983) Assessing self-maintenance: activities of daily living, mobility, and instrumental activities of daily living. J Am Geriatr Soc 31:721-727. doi:

10.1111/j.1532-5415.1983.tb03391.x

21. Kujala T, Salvucci DD (2015) Modeling visual sampling on in-car displays: The challenge of predicting safety-critical lapses of control. Int J Hum-Comput Stud 79:6678. doi: 10.1016/j.ijhcs.2015.02.009

22. Lawton MP, Brody EM (1969) Assessment of older people: Self-maintaining and instrumental activities of daily living. The Gerontologist 9:179-186. doi:

10.1093/geront/9.3_Part_1.179

23. Lee ML, Dey AK (2014) Real-time feedback for improving medication taking. In: Proceedings of the SIGCHI Conference on Human Factors in Computing Systems CHI'14. ACM Press, pp 2259-2268

24. Queirós A, Silva A, Alvarelhão J, Rocha NP, Teixeira A (2015) Usability, accessibility and ambient-assisted living: a systematic literature review. Univers Access Inf Soc 14:57-66. doi: 10.1007/s10209-013-0328-x 
25. Rashidi P, Mihailidis A (2013) A survey on ambient-assisted living tools for older adults. IEEE J Biomed Health Inform 17:579-590. doi: 10.1109/JBHI.2012.2234129

26. Riche Y, Mackay W (2010) PeerCare: Supporting awareness of rhythms and routines for better aging in place. Comput Support Coop Work 19:73-104. doi: 10.1007/s10606-0099105-z

27. Rowan J, Mynatt ED (2005) Digital family portrait field trial: Support for aging in place. In: CHI '05 Proceedings of the SIGCHI Conference on Human Factors in Computing Systems. ACM Press, pp 521-530

28. Siek KA, Khan DU, Ross SE, Haverhals LM, Meyers J, Cali SR (2011) Designing a personal health application for older adults to manage medications: A comprehensive case study. J Med Syst 35:1099-1121. doi: 10.1007/s10916-011-9719-9

29. Smith CAP, Clegg BA, Heggestad ED, Hopp-Levine PJ (2009) Interruption management: A comparison of auditory and tactile cues for both alerting and orienting. Int J Hum-Comput Stud 67:777-786. doi: 10.1016/j.ijhcs.2009.05.002

30. Trafton GJ, Monk CA (2007) Task interruptions. Rev Hum Factors Ergon 3:111-126. doi: $10.1518 / 155723408 X 299852$

31. Vastenburg MH, Keyson DV, de Ridder H (2008) Considerate home notification systems: a field study of acceptability of notifications in the home. Pers Ubiquitous Comput 12:555-566. doi: 10.1007/s00779-007-0176-x

32. Vastenburg MH, Keyson DV, de Ridder H (2009) Considerate home notification systems: A user study of acceptability of notifications in a living-room laboratory. Int $\mathbf{J}$ Hum-Comput Stud 67:814-826. doi: 10.1016/j.ijhcs.2009.06.002

33. Venkatesh V, Morris MG, Davis GB, Davis FD (2003) User acceptance of information technology: toward a unified view. MIS Q 27:425-478

34. Warnock D, McGee-Lennon M, Brewster S (2011) The role of modality in notification performance. In: Campos P, Graham N, Jorge J, Nunes N, Palanque P, Winckler M (eds) Human-Computer Interaction - INTERACT 2011. Springer, Berlin, Heidelberg, pp 572588

35. Warnock D, McGee-Lennon M, Brewster S (2013) Multiple notification modalities and older users. In: CHI '13 Proceedings of the SIGCHI Conference on Human Factors in Computing Systems. ACM Press, pp 1091-1094

36. Werner NE, Holden RJ (2015) Interruptions in the wild: Development of a sociotechnical systems model of interruptions in the emergency department through a systematic review. Appl Ergon 51:244-254. doi: 10.1016/j.apergo.2015.05.010

37. Wiley J, Sung J, Abowd G (2006) The message center: Enhancing elder communication. In: CHI '06 Extended Abstracts on Human Factors in Computing Systems. ACM Press, pp 1523-1528 
38. Wolters KM, Engelbrecht K-P, Gödde F, Möller S, Naumann A, Schleicher R (2010) Making it easier for older people to talk to smart homes: The effect of early help prompts. Univers Access Inf Soc 9:311-325. doi: 10.1007/s10209-009-0184-x 